\title{
Numerical Landscape
}

\section{Eveline Pye}

Like a tracker, I smell the earth

on my fingers, listen for the slightest

echo as I stare out at a world

where bell-shaped curves loom

as mountains and negative exponentials

foretell dangerous descents, imminent

disaster. All around, cliff edges crash

down to restless seas while a solitary

outlier shines in the southern sky: a freak

of random sampling or a guiding light?

Are others buried deep, confounded

by experimental design? On my path,

a decision tree, so many branches

spring from its trunk, so many choices.

7 Drumry Rd

Clydebank

G81 2LJ

Scotland

UK

e-mail: evelinepy@gmail.com 